\title{
A New, Soft-Switched, High-Power-Factor Boost Converter With IGBTs
}

\author{
Yungtaek Jang, Senior Member, IEEE, and Milan M. Jovanović, Fellow, IEEE
}

\begin{abstract}
A new soft-switching technique that improves performance of the high-power-factor boost rectifier by reducing switching losses is introduced. The losses are reduced by an active snubber which consists of an inductor, a capacitor, a rectifier, and an auxiliary switch. Since the boost switch turns off with zero current, this technique is well suited for implementations with insulated-gate bipolar transistors. The reverse-recovery-related losses of the rectifier are also reduced by the snubber inductor which is connected in series with the boost switch and the boost rectifier. In addition, the auxiliary switch operates with zero-voltage switching. A complete design procedure and extensive performance evaluation of the proposed active snubber using a 1.2-kW high-power-factor boost rectifier operating from a $90 \mathrm{~V}_{\mathrm{rms}}-256 \mathrm{~V}_{\mathrm{rms}}$ input are also presented.
\end{abstract}

Index Terms-Active snubber, boost converter, IGBT, power factor correction, reverse recovery loss, zero current switching, zero voltage switching.

\section{INTRODUCTION}

$\mathbf{R}$ ECENTLY, several high-speed insulated-gate bipolar transistor (IGBT) families suitable for high-frequency switch-mode-power-supply applications have been introduced. Capable of operating at switching frequencies as high as 150 $\mathrm{kHz}$ and exhibiting a relatively small conduction loss at high currents, these IGBTs appear as a viable alternative to traditionally used metal-oxide-semiconductor field-effect transistors (MOSFETs) in many high-voltage, high-current applications such as boost input-current shapers. Nevertheless, to achieve efficient and reliable operation of an IGBT, it is necessary to ensure that the IGBT is switched under favorable switching conditions. Specifically, due to the IGBT's collector current "tail" effect during the turn-off, which increases the turn-off switching loss and limits the maximum switching frequency, the optimal performance of the IGBT can be achieved by turning-off the IGBT at zero current [1].

A zero-current-switching (ZCS) boost converter suitable for applications with IGBTs was introduced in [2]. Although in this circuit the boost switch is turned off at zero current, the circuit exhibits a strong undesirable resonance between the snubber inductor and the output capacitance of the switches, which requires additional clamp and/or snubber circuits [3].

In this paper, a soft-switching technique which is suitable for IGBT applications, and which does not suffer from undesirable resonances of circuit's components is proposed. The proposed

Manuscript received May 20, 1999; revised January 9, 2002. Recommended by Associate Editor L. Moran.

The authors are with the Delta Products Corporation, Power Electronics Laboratory, Research Triangle Park, NC 27709 USA.

Publisher Item Identifier 10.1109/TPEL.2002.801002.

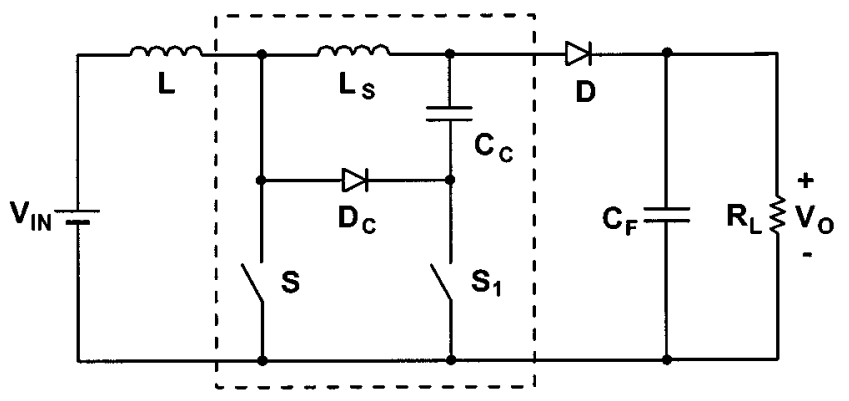

Fig. 1. Boost power stage with new ZC-ZVS active snubber.

technique improves the performance of the boost input-current shaper by eliminating the switching losses with a new zero-current-zero-voltage-switched (ZC-ZVS) active-snubber circuit that consists of a snubber inductor, a clamp diode, a clamp capacitor, and an auxiliary switch. The ZC-ZVS snubber reduces the reverse-recovery-related losses of the rectifier and also provides soft switching of the main and auxiliary switches. Specifically, the main switch turns off with ZCS, whereas the auxiliary switch turns on with ZVS. In addition, because the proper operation of the ZC-ZVS snubber requires that the conduction period of the main switch and the auxiliary switch overlap, the proposed boost converter with active snubber is not susceptible to failures due to accidental transient overlapping of the main and auxiliary switch gate drives. Moreover, the complexity and cost of the converters using the proposed technique is further reduced because the proposed ZC-ZVS active snubber requires a simple nonisolated (direct) gate drive for both switches.

Finally, a complete design procedure of the proposed soft-switched boost converter as well as extensive experimental evaluations of its performance are presented. The evaluation was performed on a single-phase, $1.2-\mathrm{kW}, 80-\mathrm{kHz}$, high-power-factor boost rectifier operating in the universal line voltage range of $90 \mathrm{~V}_{\mathrm{rms}}-265 \mathrm{~V}_{\mathrm{rms}}$.

\section{ANALYSIS OF OPERATION}

The circuit diagram of the boost converter that employs the new ZC-ZVS active snubber is shown in Fig. 1. The circuit in Fig. 1 uses snubber inductor $L_{S}$, which is connected in series with main switch $S$ and rectifier $D$, to control the $d i / d t$ rate of the rectifier. Along with $S$, and $L_{S}$, auxiliary switch $S_{1}$, clamp capacitor $C_{C}$, and clamp diode $D_{C}$ form a ZC-ZVS active snubber as indicated by dashed lines in Fig. 1.

To simplify the analysis of operation, it is assumed that the inductance of boost inductor $L$ is large so that it can be represented by constant-current source $I_{\mathrm{IN}}$, and that the output-ripple 


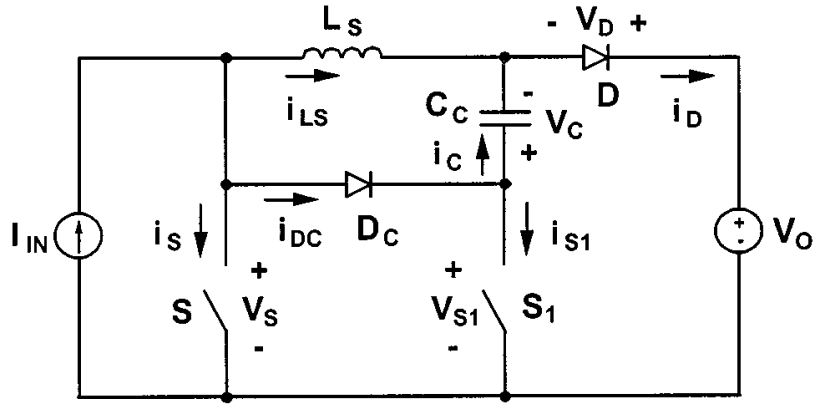

Fig. 2. Simplified circuit diagram of the proposed boost power stage showing reference directions of currents and voltages.

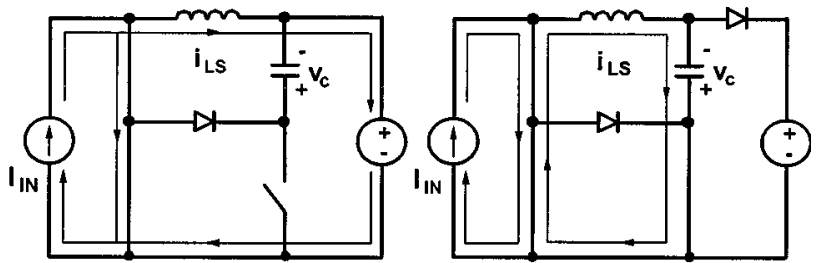

(a) $\left[T_{0}-T_{1}\right]$

(f) $\left[T_{5}-T_{6}\right]$

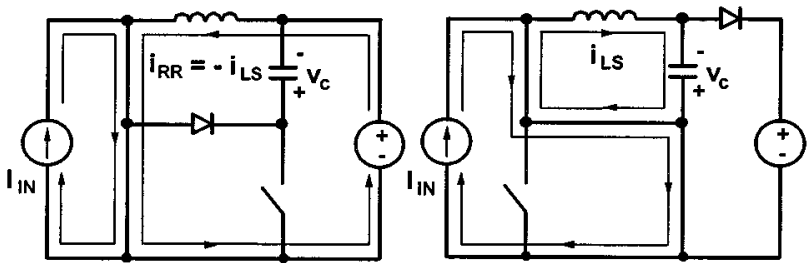

(b) $\left[T_{1}-T_{2}\right]$

(g) $\left[T_{6}-T_{7}\right]$

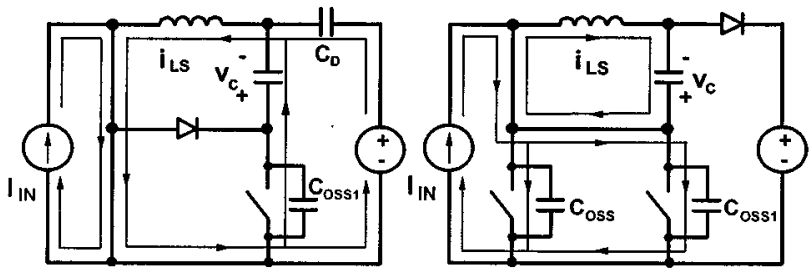

(c) $\left[T_{2}-T_{3}\right]$

(h) $\left[T_{7}-T_{8}\right]$
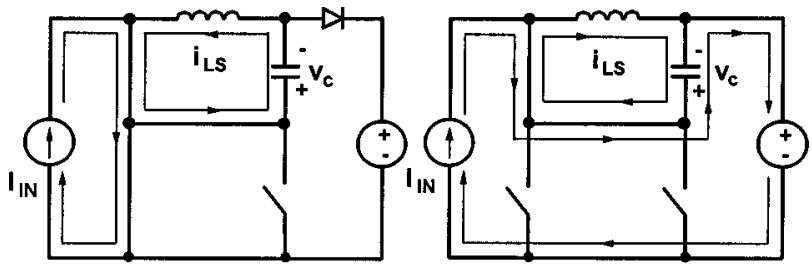

(d) $\left[T_{3}-T_{4}\right]$

(i) $\left[T_{8}-T_{9}\right]$

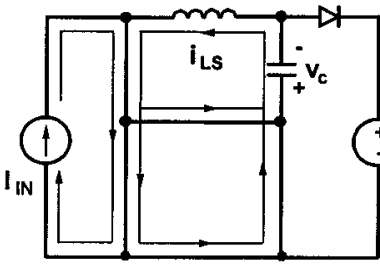

(e) $\left[T_{4}-T_{5}\right]$

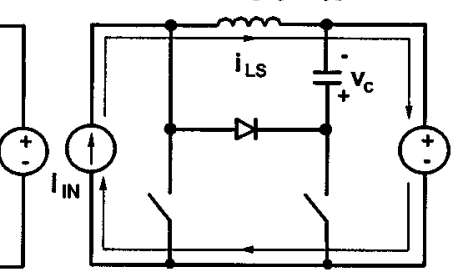

(j) $\left[T_{9}-T_{10}\right]$
Fig. 3. Topological stages of the proposed boost power stage when the peak resonant current $I_{\mathrm{LS}(\mathrm{PK})}$ is smaller than input current $I_{\mathrm{IV}}$.

voltage is negligible so that the voltage across the output filter capacitor can be represented by constant-voltage source $V_{O}$. Also, it is assumed that in the on state, semiconductors exhibit

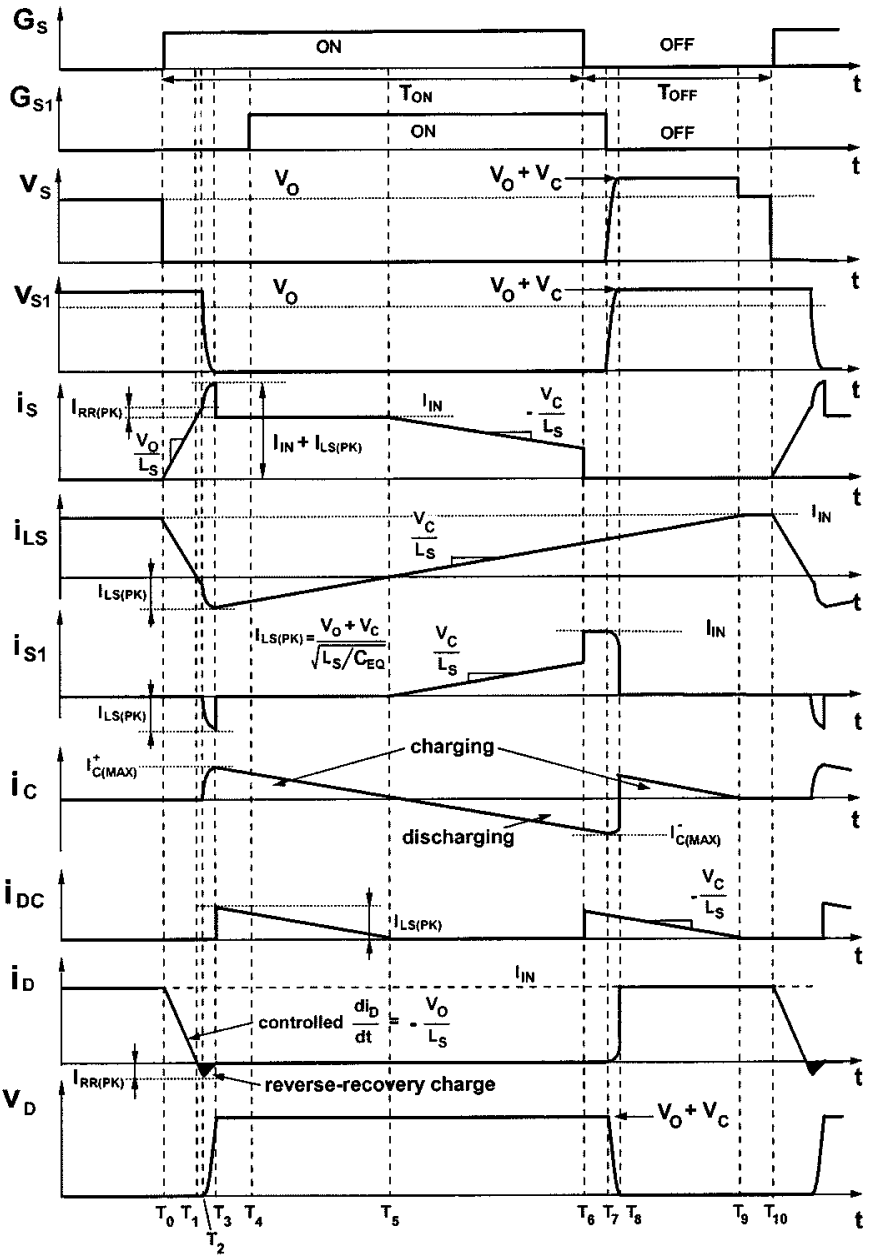

Fig. 4. Key waveforms of the proposed boost power stage when the peak resonant current $I_{\mathrm{LS}(\mathrm{PK})}$ is smaller than input current $I_{\mathrm{IN}}$.

zero resistance, i.e., they are short circuits. However, the output capacitance of the switches and the reverse-recovery charge of the rectifier are not neglected in this analysis. The circuit diagram of the simplified converter is shown in Fig. 2.

To further facilitate the explanation of the operation, Fig. 3 shows topological stages of the circuit in Fig. 1 during a switching cycle, whereas Fig. 4 shows the power-stage key waveforms. As can be seen from the gate-drive timing diagrams for the boost and auxiliary switches in Fig. 4, the proposed circuit operates with an overlapping gate drive of the switches where the main switch turns on and off slightly prior to the auxiliary switch, i.e., both switches conduct simultaneously during the major period of the on-time and share the current.

Before main switch $S$ is turned on at $t=T_{0}$, the entire input current $I_{\mathrm{IN}}$ flows through snubber inductor $L_{S}$ and boost rectifier $D$. At the same time, main switch $S$ is off blocking output voltage $V_{O}$, whereas, auxiliary switch $S_{1}$ is off blocking a voltage which is the sum of output voltage $V_{O}$ and clamp-capacitor voltage $V_{C}$, i.e., $V_{O}+V_{C}$.

After switch $S$ is turned on at $t=T_{0}$, a constant voltage $V_{O}$ is applied across $L_{S}$, as shown in the equivalent circuit in Fig. 3(a). As a result, inductor current $i_{\mathrm{LS}}$ and rectifier current $i_{D}$ decrease linearly, whereas switch current $i_{S}$ increases at the 
same rate. The rate of the rectifier current decrease is governed by

$$
\frac{d i_{D}}{d t}=-\frac{V_{O}}{L_{S}}
$$

Since the rate of the boost-rectifier-current decrease is controlled by snubber inductance $L_{S}$, the rectifier recovered charge and the associated losses can be reduced by a proper selection of the $L_{S}$ inductance. Generally, a larger inductance, which gives a lower $d i_{D} / d t$ rate, results in a more efficient reduction of the reverse recovery-associated losses [4].

At $t=T_{1}$, when $i_{\mathrm{LS}}$ and $i_{D}$ decrease to zero, the entire input current $I_{\mathrm{IN}}$ flows through switch $S$, as shown in Fig. 4. Ideally, when $i_{D}$ falls to zero at $t=T_{1}$, rectifier $D$ should stop conducting. However, due to a residual stored charge, reverse-recovery current $i_{\mathrm{RR}}$ will flow through rectifier $D$, as shown in Fig. 3(b). When, at $t=T_{2}$, the stored charge is recovered from the junction of rectifier $D$ and the rectifier regains its blocking capability, a resonant circuit consisting of snubber inductor $L_{S}$, snubber capacitor $C_{C}$, output capacitor $C_{\mathrm{OSS} 1}$ of auxiliary switch $S_{1}$, and junction capacitor $C_{D}$ of rectifier $D$ is formed, as shown in Fig. 3(c). As a result, during the $T_{2}-T_{3}$ interval, the drain voltage of auxiliary switch $S_{1}$ decreases from $V_{O}+V_{C}$ to zero in a resonant fashion. At $t=T_{3}$, when $V_{S 1}$ falls to zero, peak resonant current $I_{\mathrm{LS}(\mathrm{PK})}$, which flows in the negative direction through $L_{S}$, is given by

$$
I_{\mathrm{LS}(\mathrm{PK})}=i_{\mathrm{LS}}\left(t=T_{3}\right)=\frac{V_{O}+V_{C}}{\sqrt{\frac{L_{S}}{C_{E Q}}}}
$$

where $C_{E Q}=C_{\mathrm{OSS} 1} C_{C} /\left(C_{\mathrm{OSS} 1}+C_{C}\right)+C_{D} \approx C_{\mathrm{OSS} 1}+C_{D}$ because for a properly designed circuit $C_{C} \gg C_{\mathrm{OSS} 1}$. From Fig. 3(c), the peak current of clamp capacitor $C_{C}$ at $t=T_{3}$, $I_{C(\mathrm{MAX})}^{+}$, is

$$
\begin{aligned}
I_{C(\mathrm{MAX})}^{+} & =i_{C}\left(t=T_{3}\right) \\
& =\frac{C_{\mathrm{OSS} 1}}{C_{\mathrm{OSS} 1}+C_{D}} \times \frac{V_{O}+V_{C}}{\sqrt{\frac{L_{S}}{C_{E Q}}}} .
\end{aligned}
$$

After the voltage across auxiliary switch $S_{1}$ falls to zero at $t=$ $T_{3}$, clamp diode $D_{C}$ starts conducting, as shown in Fig. 3(d). When $D_{C}$ is conducting, clamp capacitor voltage $V_{C}$ is applied across $L_{S}$ and snubber-inductor current $i_{\mathrm{LS}}$ increases linearly, as illustrated in Fig. 4. If the capacitance of clamp capacitor $C_{C}$ is large, capacitor voltage $V_{C}$ is almost constant so that inductor current $i_{\mathrm{LS}}$ increases and capacitor current $i_{C}$ decreases linearly, i.e., $d i_{\mathrm{LS}} / d t=-d i_{C} / d t=V_{C} / L_{S}$. Otherwise, $i_{\mathrm{LS}}$ and $i_{C}$ change in a resonant fashion. This topological stage ends at $t=T_{5}$, when $i_{C}$ reaches zero and clamp diode $D_{C}$ stops conducting. As can be seen from Fig. 4, to achieve ZVS of auxiliary switch $S_{1}$, it is necessary to turn on $S_{1}$ before $t=T_{5}$, i.e., $S_{1}$ should be turned on while clamp diode $D_{C}$ is conducting. In Fig. 4, auxiliary switch $S_{1}$ is turned on at $t=T_{4}$. It should be noted that after $t=T_{4}$, current $i_{\mathrm{LS}}$ or a part of it may continue flowing through $S_{1}$ depending on the relative values of on-impedances of $S_{1}$ and $D_{C}$, as shown in Fig. 3(e). Since auxiliary switch $S_{1}$ starts conducting after clamp diode $D_{C}$ ceases to conduct at $t=T_{5}$, auxiliary-switch current $i_{S 1}$ continues to increase linearly, as illustrated in Fig. 3(f). At the same time, main-switch current $i_{S}$ decreases at the same rate because the sum of $i_{S 1}$ and $i_{S}$ is equal to the constant input current $I_{\mathrm{IN}}$.

When main switch $S$ is turned off at $t=T_{6}$, the current which was flowing through switch $S$ is diverted to auxiliary switch $S_{1}$ through clamp diode $D_{C}$ as shown in Fig. 3(g). It should be noted that at the moment of switch $S$ turn-off at $t=T_{6}$, the current of $S$ is smaller than $I_{\mathrm{IN}}$, as shown in Fig. 4. In addition, the voltage across switch $S$ during its turn-off is clamped to zero by conducting clamp diode $D_{C}$ and auxiliary switch $S_{1}$, as can be seen from Fig. 3(g). As a result, switch $S$ is turned off with a greatly reduced channel current and with zero voltage. In fact, the circuit can be designed to achieve complete ZCS of main switch $S$ during the turn-off time, as it will be discussed later. During the $T_{6}-T_{7}$ interval, input current $I_{\mathrm{IN}}$ flows through $S_{1}$, whereas $C_{C}$ continues to discharge through $L_{S}$. This interval ends at $t=T_{7}$ when auxiliary switch $S_{1}$ is turned off. It should be noted that auxiliary switch $S_{1}$ shares the input current with main switch $S$ during the time interval between $t=T_{5}$ and $t=T_{6}$, as shown in Figs. 3(f) and 4. Therefore, by the addition of auxiliary switch $S_{1}$, the overall rms current of main switch $S$ is reduced.

After switch $S_{1}$ is turned off at $t=T_{7}$, current $I_{\mathrm{IN}}$ flowing through switch $S_{1}$ is diverted from the switch to its output capacitance $C_{\mathrm{OSS} 1}$, as shown in Fig. 3(h). As a result, the voltage across auxiliary switch $S_{1}$ starts to increase linearly from zero to $V_{O}+V_{C}$ due to the constant charging current $I_{\mathrm{IN}}$. At the same time, because of conducting $D_{C}$, voltage $V_{S}$ of main switch $S$ also increases from zero toward $V_{O}+V_{C}$. When the voltage across switches $S$ and $S_{1}$ reaches $V_{O}+V_{C}$ at $t=T_{8}$, rectifier $D$ starts conducting, as shown in Fig. 3(i). During the $T_{8}-T_{9}$ time interval, $i_{\mathrm{LS}}$ continues to increase toward $I_{\mathrm{IN}}$, while clamp capacitor $C_{C}$ is being charged by the difference of input current $I_{\mathrm{IN}}$ and snubber inductor current $i_{\mathrm{LS}}$, i.e., by $I_{\mathrm{IN}}-i_{\mathrm{LS}}$. When, at $t=T_{9}, i_{\mathrm{LS}}$ reaches $I_{\mathrm{IN}}$, clamp diode $D_{C}$ stops conducting and the entire input current flows through $D$, as shown in Fig. 3(j). The circuit stays in this topological stage until the next switching cycle is initiated at $t=T_{10}$.

At light load operation, when input current $I_{\mathrm{IN}}$ is smaller than the peak resonant current $I_{\mathrm{LS}(\mathrm{PK})}$ described in (2), the charge balance of clamp capacitor $C_{C}$ is completed during switch-on period. Figs. 5 and 6 show the power-stage operation when $I_{\mathrm{IN}}$ is smaller than $I_{\mathrm{LS}(\mathrm{PK})}$. Fig. 5 shows topological stages during a switching cycle, whereas Fig. 6 shows the power-stage key waveforms.

During the $T_{0}-T_{5}$ interval, the key waveforms and powerstage operation when $I_{\mathrm{IN}}$ is smaller than $I_{\mathrm{LS}(\mathrm{PK})}$ are the same as in the case when $I_{\mathrm{IN}}$ is greater than $I_{\mathrm{LS}(\mathrm{PK})}$, Figs. 3 and 4. However, after $t=T_{5}$, the operation when $I_{\mathrm{IN}}$ is smaller than $I_{\mathrm{LS}(\mathrm{PK})}$ is different from that shown in Figs. 3 and 4. Since when $I_{\mathrm{IN}}$ is smaller than $I_{\mathrm{LS}(\mathrm{PK})}$, snubber-inductor current $i_{\mathrm{LS}}$ reaches $I_{\mathrm{IN}}$ level before main switch $S$ turned off at $t=T_{6}$, auxiliary switch $S_{1}$ carries the entire input current during the $T_{6}-T_{8}$ interval as shown in Fig. 6. Therefore, to achieve a complete ZCS of the main switch, the peak resonant current $I_{\mathrm{LS}(\mathrm{PK})}$ should be designed to be greater than input current $I_{\mathrm{IN}}$ over the entire load and line range. 


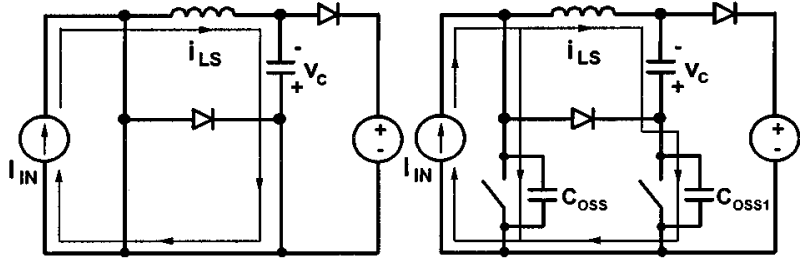

(a) $\left[T_{6}-T_{7}\right]$

(c) $\left[T_{8}-T_{9}\right]$

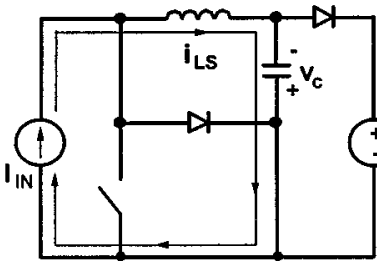

(b) $\left[T_{7}-T_{8}\right]$

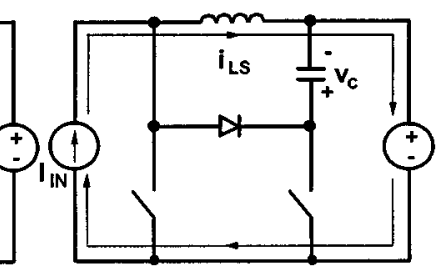

(d) $\left[T_{9}-T_{10}\right]$

Fig. 5. Topological stages of the proposed boost power stage when $I_{\mathrm{IV}}$ is smaller than the peak resonant current $I_{\mathrm{LS}(\mathrm{PK})}$.

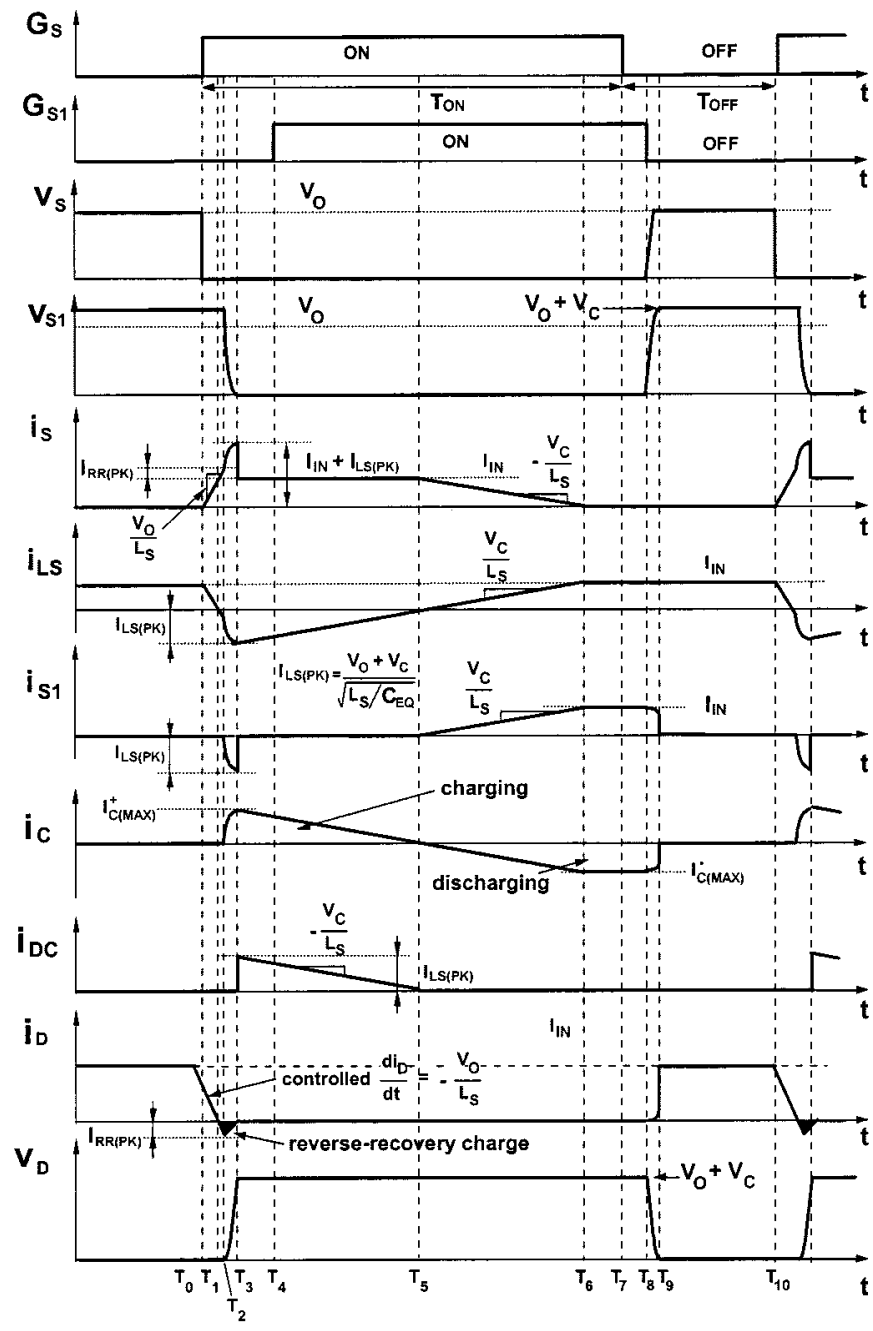

Fig. 6. Key waveforms of the proposed boost power stage when $I_{\text {IN }}$ is smaller than the peak resonant current $I_{\mathrm{LS}(\mathrm{PK})}$.

As can be seen from the waveforms in Fig. 4, to achieve a complete ZCS turn-off of main switch $S$, it is necessary that current through clamp capacitor $i_{C}$ at the moment when $S$ is turned off is equal to input current $I_{\mathrm{IN}}$, i.e.

$$
i_{C}\left(t=T_{6}\right)=I_{\mathrm{IN}} \text {. }
$$

Moreover, since for a properly designed circuit the $T_{6}-T_{7}$ time interval is much shorter than the $T_{5}-T_{6}$ time interval in Fig. 4, the value of clamp capacitor current $i_{C}$ at $t=T_{6}$ and $t=T_{7}$ is approximately the same, i.e.

$$
i_{C}\left(t=T_{6}\right) \approx i_{C}\left(t=T_{7}\right)=I_{C(\mathrm{MAX})}^{-} .
$$

where $I_{C M A X}$ is the maximum discharging current, as indicated on the $i_{C}$ waveform in Fig. 4. From (4) and (5), the ZCS condition for $S$ can be defined as

$$
I_{C(\mathrm{MAX})}^{-}=I_{\mathrm{IN}} \text {. }
$$

Since for the circuit design wherein $I_{C \mathrm{MAX}}^{-}=I_{\mathrm{IN}}, C_{C}$ charging occurs only during the $T_{2}-T_{5}$ interval, i.e., the charging interval $T_{8}-T_{9}$ shown in Fig. 4 does not exist, the charge balance of $C_{C}$ requires that

$$
I_{C(\mathrm{MAX})}^{+}=i_{C}\left(t=T_{3}\right) \approx I_{C(\mathrm{MAX})}^{-} \approx I_{\mathrm{IN}} .
$$

From (3) and (7), the ZCS condition can be written as

$$
\frac{1}{C_{\mathrm{OSS} 1}} \sqrt{L_{S}\left(C_{\mathrm{OSS} 1}+C_{D}\right)} \leq \frac{V_{O}+V_{C}}{I_{\mathrm{IN}}} .
$$

If (8) is satisfied at the maximum power, i.e., for $I_{\mathrm{IN}}=I_{\mathrm{IN}(\mathrm{MAX})}$, complete ZCS of switch $S$ is achieved in the full load range. It should be noted that because auxiliary switch $S_{1}$ and rectifier $D$ are both turned on under ZVS condition, external capacitance can be added across $S_{1}$ or $D$ without incurring additional switching losses. If it is necessary to satisfy (8) for given $V_{O}, I_{\mathrm{IN}(\mathrm{MAX})}, L_{S}, V_{C}$, and for given $C_{\mathrm{OSS} 1}$ and $C_{D}$, external capacitance can be added in parallel with $C_{\mathrm{OSS} 1}$ or $C_{D}$. However, since main switch $S$ is always turned off with ZVS, the complete ZCS of main switch $S$ is not necessary to improve overall performance of the converter. Therefore, the main switch current during turn-off (at $t=T_{6}$ in Fig. 4) needs to be optimized so that the peak resonant current $I_{\mathrm{LS}(\mathrm{PK})}$ is not excessive.

As can be seen from Fig. 4, the voltage stress of main switch $S$, auxiliary switch $S_{1}$, and rectifier $D$ is $V_{O}+V_{C}$. Therefore, the voltage stress of main switch $S$ in the proposed converter is higher compared to the corresponding stress in the conventional, "hard"-switched boost converter. To keep the voltage stress of switch $S$ and switch $S_{1}$ within reasonable limits, it is necessary to select clamp-voltage level $V_{C}$ properly.

The derivation of $V_{C}$ dependence on the circuit parameters can be simplified by recognizing that in the boost converter in Fig. 1 that is designed to minimize the reverse-recovery-related losses and achieve complete ZCS of main switch $S$, the rectifier-current commutation interval $T_{0}-T_{2}$ is much shorter than on-time period $T_{\mathrm{ON}}$ of switch $S$, and that capacitor charging period $T_{8}-T_{9}$ is zero. In addition, the duration of the commutation periods $T_{2}-T_{3}$ and $T_{7}-T_{8}$ are negligible compared to the on-time interval of main switch $S$.

From Fig. 4, it can be seen that, from $t=T_{3}$ to $t=T_{5}$, clamp capacitor $C_{C}$ is charged with current $i_{C}$ which has a constant slope of $d i_{C} / d t=V_{C} / L_{S}$. Therefore, since the circuit is designed to achieve ZCS of main switch $S, i_{C}\left(t=T_{3}\right)=$ $I_{C \mathrm{MAX}}^{+}=I_{\mathrm{IN}}$, and since the duration of the time interval from $t=T_{2}$ to $t=T_{5}$ is approximately one-half of the on-time of switch $S$, clamp-capacitor voltage $V_{C}$ can be expressed as

$$
V_{C} \approx L_{S} \frac{I_{\mathrm{IN}}}{\frac{D T_{S}}{2}}=2 \frac{L_{S} f_{S} I_{\mathrm{IN}}}{D}
$$


where $D$ is the duty-cycle of switch $S, T_{S}$ is the switching period, and $f_{S}$ is the switching frequency. Since for a lossless boost power stage for which the current commutation interval $T_{0}-T_{2}$ is much shorter than $T_{\mathrm{ON}}$, the voltage-conversion ratio $V_{O} / V_{\mathrm{IN}}$ is given by

$$
\frac{V_{O}}{V_{\mathrm{IN}}}=\frac{I_{\mathrm{IN}}}{I_{O}}=\frac{1}{1-D} .
$$

Equation (10) can be written as

$$
V_{C} \approx 2 L_{S} f_{S} I_{O}\left(\frac{V_{O}^{2}}{\left(V_{O}-V_{\mathrm{IN}}\right) V_{\mathrm{IN}}}\right) .
$$

According to (11), $V_{C}$ is maximum at full load $I_{\mathrm{O}(\mathrm{MAX})}$ and high line $V_{\mathrm{IN}(\mathrm{MAX})}$. For given input and output specifications, i.e., for given $I_{\mathrm{O}(\mathrm{MAX})}, V_{\mathrm{IN}(\mathrm{MAX})}$, and $V_{O}$, clamp-capacitor voltage $V_{C}$ can be minimized by minimizing the $L_{S} f_{S}$ product.

It should be noted that the control of the proposed boost converter can be implemented in the same way as in its conventional "hard" switched counterpart as long as an additional gate-drive circuit is provided. Specifically, in the input-current-shaping applications, the proposed converter can be implemented with any known control technique, such as average current, peak current, or hysteretic control.

\section{Design OF A 1.2-KW, HPF BoOst Rectifier PROTOTyPe}

A 1.2-kW, HPF boost experimental rectifier was designed for the following specifications.

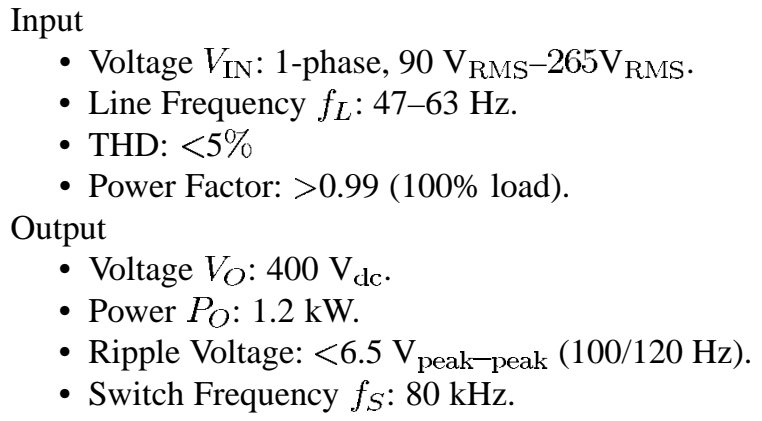

\section{A. Design of Active Snubber Circuit}

The analysis of the proposed soft-switching technique described in Section II can be applied to ac/dc PFC boost rectifiers. Since the switching frequency is much higher than the line frequency, the rectified ac input voltage of the boost rectifier is approximately constant during a switching cycle, and can be approximated as a dc voltage source.

To reduce the reverse-recovery-related losses, the $d i_{D} / d t$ rate of the majority of fast-recovery rectifiers should be kept below approximately $100 \mathrm{~A} / \mu \mathrm{s}$ [4]. Generally, slower rectifiers require slower $d i_{D} / d t$ rates than faster rectifiers to achieve the same level of reduction of the reverse-recovery-related losses. As a rule of thumb, the practical range of snubber inductance $L_{S}$ is from $2 \mu \mathrm{H}$ to $20 \mu \mathrm{H}$. In fact, without a snubber, the rate of rectifier-current change is mainly decided by the parasitic inductance of the trace between boost switch $S$ and rectifier $D$, which is generally less than several hundreds nanohenrys. As a result, the rate of rectifier-current change of the boost rectifier without a snubber inductor is approximately $2000 \mathrm{~A} / \mu \mathrm{s}\left(V_{O} / L_{P}=\right.$ $\left.400 / 0.2 \times 10^{-6}\right)$. To reduce the stored charge which is directly proportional to the reverse-recovery-related losses, snubber inductor $L_{S}$ must be added.

Generally, the maximum value of snubber inductance $L_{S}$ is limited by the voltage stress on switch $S$ and auxiliary switch $S_{1}$. As can be seen from Figs. 2 and 4, the voltage stress of switches $S$ and $S_{1}$ are the same and equal to $V_{O}+V_{C}$. During the period when clamp diode $D_{C}$ is not conducting, auxiliary switch $S_{1}$ blocks the voltage which is the summation of the clamp capacitor voltage and the output voltage. Boost switch $S$ blocks the same voltage when clamp diode $D_{C}$ is conducting. Compared to the corresponding stress in the conventional, "hard"-switched boost converter, the voltage stress of boost switch $S$ in the proposed converter is higher for the amount of clamp voltage $V_{C}$. To keep the voltage stress of switches $S$ and $S_{1}$ within reasonable limits, it is necessary to properly select clamp-voltage level $V_{C}$. Clamp-capacitor voltage $V_{C}$ can be calculated by using (11). According to (11), $V_{C}$ is the maximum at full load $I_{\mathrm{O}(\mathrm{MAX})}$ and high line $V_{\mathrm{IN}(\mathrm{MAX})}$, since switching frequency $f_{S}$ and output voltage $V_{O}$ are constant. For given input and output specifications, i.e., for given $I_{\mathrm{O}(\mathrm{MAX})}$, $V_{\mathrm{IN}(\mathrm{MAX})}, f_{S}$, and $V_{O}$, the voltage stresses on the main and auxiliary switches can be minimized by minimizing snubber inductor $L_{S}$. From the specifications, the maximum input voltage $V_{\mathrm{IN}(\mathrm{MAX})}=375 \mathrm{~V}$, the maximum output current $I_{O(\mathrm{MAX})}=3 \mathrm{~A}$, switching frequency $f_{S}=80 \mathrm{kHz}$, and output voltage $V_{O}=400 \mathrm{~V}$. To reduce $d i_{D} / d t$ rate the value of snubber inductor $L_{S}$ was chosen to be approximately $3.3 \mu \mathrm{H}$. This value results in $d i_{D} / d t=120 \mathrm{~A} / \mu$ s and $V_{C}=27 \mathrm{~V}$. The maximum voltage stress of the switch is below $427 \mathrm{~V}$ which is quite acceptable even for a 500-V rated device.

Since the average voltage across the clamp-capacitor is independent from the size of the clamp capacitor $C_{C}$ as shown in (11), the value of $C_{C}$ can be selected to minimize the switch-frequency voltage ripple. Since the energy stored in the snubber inductor contributes to the voltage ripple during a switching cycle, the maximum switch-frequency voltage ripple $V_{C(P-P)}$ can be expressed as

$$
V_{C(P-P)}=I_{O(\max )} \sqrt{\frac{L_{S}}{C_{C}}} .
$$

The choice of two $6.8 \mu \mathrm{F} / 100 \mathrm{~V}$ ceramic capacitors in parallel for the clamp capacitor limits the magnitude of the maximum peak-to-peak ripple voltage to approximately $1.5 \mathrm{~V}$, which is less than $20 \%$ of $V_{C}$ over the entire input voltage and load range.

\section{B. Selection of Components}

Semiconductors: The peak voltage stress on switch $S$ is approximately $430 \mathrm{~V}$ as explained in Section III-A. The peak current stress on $S$, which is equal to the peak input current is approximately $I_{\mathrm{IN}(\mathrm{MAX})}=\sqrt{2} P_{O} /\left(\eta \times P F \times V_{\mathrm{IN}}\right)=$ $\sqrt{2} \times 1200 /(0.92 \times 0.99 \times 90) \cong 21 \mathrm{~A}$ at full load and low line. An IXGK 50N60B IGBT from IXYS $\left(V_{\mathrm{CES}}=600 \mathrm{~V}\right.$, $I_{\mathrm{C} 90}=50 \mathrm{~A}, V_{F}=2.5 \mathrm{~V}$ ) is used for boost switch $S$. The peak voltage stress on auxiliary switch $S_{1}$ is the same as that of switch $S$. Also, the peak current stress on $S_{1}$ is equal to the peak current stress of $S$, i.e., it is equal to the input current at full load and low line. However, the average current of $S_{1}$, 
$\left\langle i_{S 1}\right\rangle$, is much smaller than the average current of $S,\left\langle i_{S}\right\rangle$, as can be seen from Fig. 4. As a result, a smaller IGBT can be selected for $S_{1}$. In the experimental circuit, an HGTG 20N60B3 IGBT from Harris $\left(V_{\mathrm{CES}}=600 \mathrm{~V}, I_{\mathrm{C} 110}=20 \mathrm{~A}, V_{F}=2 \mathrm{~V}\right)$ is used for $S_{1}$. Although $S_{1}$ turns on with ZVS and can be implemented with a MOSFET device, in the experimental circuit an IGBT is also used for auxiliary switch $S_{1}$ together with boost switch $S$. To reduce the turn-off switching loss of $S_{1}$ and optimize the peak value of snubber-inductor current $I_{\mathrm{LS}(\mathrm{PK})}$, capacitor $C_{P}(200 \mathrm{pF} / 1 \mathrm{kV})$ is connected in parallel with $S_{1}$. Specifically, the value of capacitor $C_{P}$ is chosen so that $I_{\mathrm{LS}(\mathrm{PK})}$ is approximately equal to input current $I_{\mathrm{IN}}$, in order to achieve ZCS turn-off of $S$, as seen in Fig. 4. Generally, the output capacitance of a similarly rated MOSFET switch is approximately five times larger than that of a IGBT switch. As a result, an additional capacitor is not required when a MOSFET switch is utilized for $S_{1}$.

Since, output diode $D$ has the same voltage stress as that of switch $S$ and must conduct a maximum load current of $3 \mathrm{~A}$, two RHRP3060 diodes from Harris $\left(V_{\mathrm{RRM}}=600 \mathrm{~V}, I_{\mathrm{FAVM}}=\right.$ $30 \mathrm{~A}, t_{\mathrm{rr}}=40 \mathrm{~ns}$ ) connected in parallel were used for output diode $D$. To reduce the conduction loss of the output diode, the devices which have a significantly higher current rating than the maximum current were selected. The voltage stress of clamp diode $D_{C}$ is the same as that of output diode $D$. However, since the circulating current through $L_{S}-D_{C}$ loop is small, a RHRP3060 diode is used for $D_{C}$.

Boost Inductor: Since the desired inductance of boost inductor $L$ is $0.5 \mathrm{mH}$, four $0.125 \mathrm{mH}$ inductors are built using a toroidal core (Magnetics, Kool- $\mu$ 77 071-A7) and 45 turns of magnet wire (AWG \#12). Four small-size cores are used to reduce the overall height of the power supply.

Snubber Inductor: Snubber inductor $L_{S}=3.3 \mu \mathrm{H}$ was built using a toroidal core (Magnetics, Kool- $\mu$ 77 312-A7) and 12 turns of magnet wire (AWG \#12).

Clamp Capacitor: Two $6.8 \mu \mathrm{F}, 100 \mathrm{VDC}$, ceramic capacitors connected in parallel are used for clamp capacitor $C_{C}$ to limit the magnitude of the maximum peak-to-peak ripple voltage to approximately $1.5 \mathrm{~V}$. Since the peak clamping capacitor voltage is approximately $30 \mathrm{~V}$ for this prototype, 100 VDC ceramic capacitors are utilized.

\section{EVALUATION}

The component values of the experimental circuit power stage are shown in Fig. 7. The control circuit was implemented with the average-current PFC controller UC3854. The TC427 driver is used to generate the required gate-drive signal for the main switch and the auxiliary switch. The value of resistor $R_{D}$ is selected large enough so that it doesn't affect normal circuit operation. Resistor $R_{D}$ is added to discharge capacitor $C_{C}$ when the PFC boost rectifier is no longer operating.

Fig. 8 shows the oscillograms of key waveforms of the experimental converter with the IGBT implementation at the low line and full power. The oscillograms in Fig. 8 is taken at the peak of the line current, i.e., when the duty cycle is at the minimum. As can be seen comparing corresponding waveforms in Figs. 4 and 8 , there is a good agreement between the experimental and

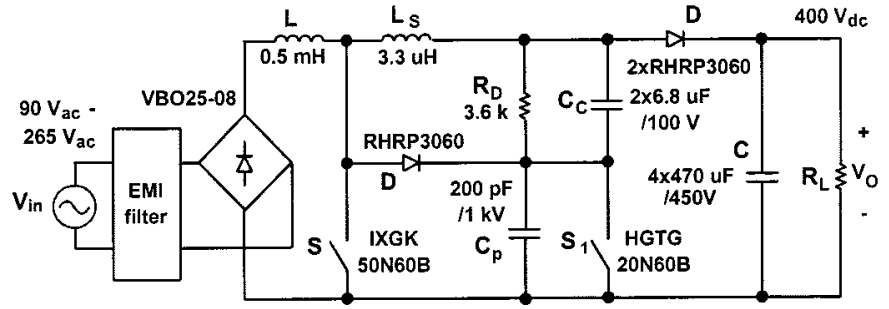

Fig. 7. Experimental $1.2 \mathrm{~kW}$, boost power stage with a ZC-ZVS active snubber.
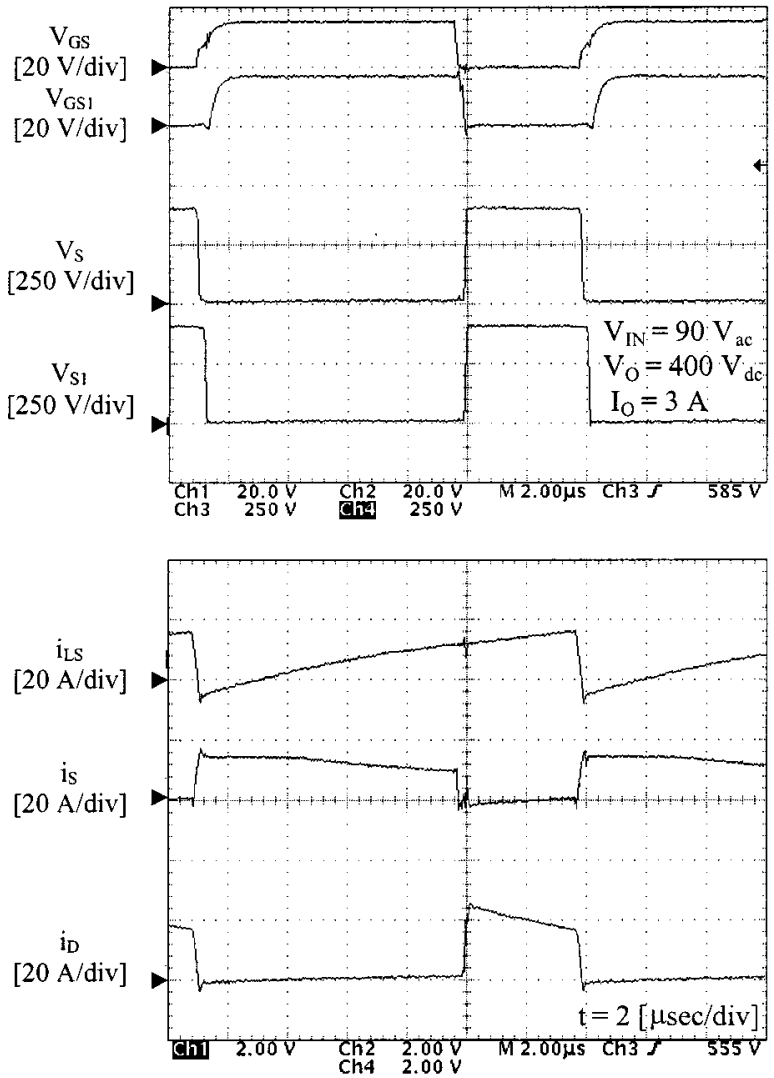

Fig. 8. Measured key waveforms of experimental converter at $P_{O}=1.2 \mathrm{~kW}$ and $V_{\mathrm{IN}}=90 \mathrm{~V}_{\text {rms. }}$. Time base: $2 \mu \mathrm{s} / \mathrm{div}$.

theoretical waveforms. As can be seen from Fig. 8, auxiliary switch $S_{1}$ is turned on with ZVS since its voltage $V_{S 1}$ falls to zero before gate-drive signal $V_{\mathrm{GS} 1}$ becomes high. However, boost switch $S$ is turned on while voltage across it is equal to output voltage $V_{O}=400 \mathrm{~V}$. Despite this "hard" turn on of boost switch $S$, all waveforms are free from parasitic ringing, since the output capacitance of IGBTs is much smaller than that of MOSFETs. In fact, since the overall switching loss of IGBTs is dominated by its turn-off loss due to the current tailing effect, the optimum switching strategy of IGBT is soft turn off, rather than soft turn on. As shown in Figs. 8 and 9, when switch $S$ is turned off, switch current $i_{S}$ is small and drain to source voltage $V_{S}$ is clamped to zero until switch $S_{1}$ is turned off. Therefore, the turn-off loss of switches is very much reduced. Also, it should be noted that the boost-rectifier-current turn-off rate, which is controlled by $L_{S}$, is approximately $d i_{D} / d t=120 \mathrm{~A} / \mu \mathrm{s}$, as indicated in Fig. 8. With this $d i_{D} / d t$ rate, peak reverse-recovery 

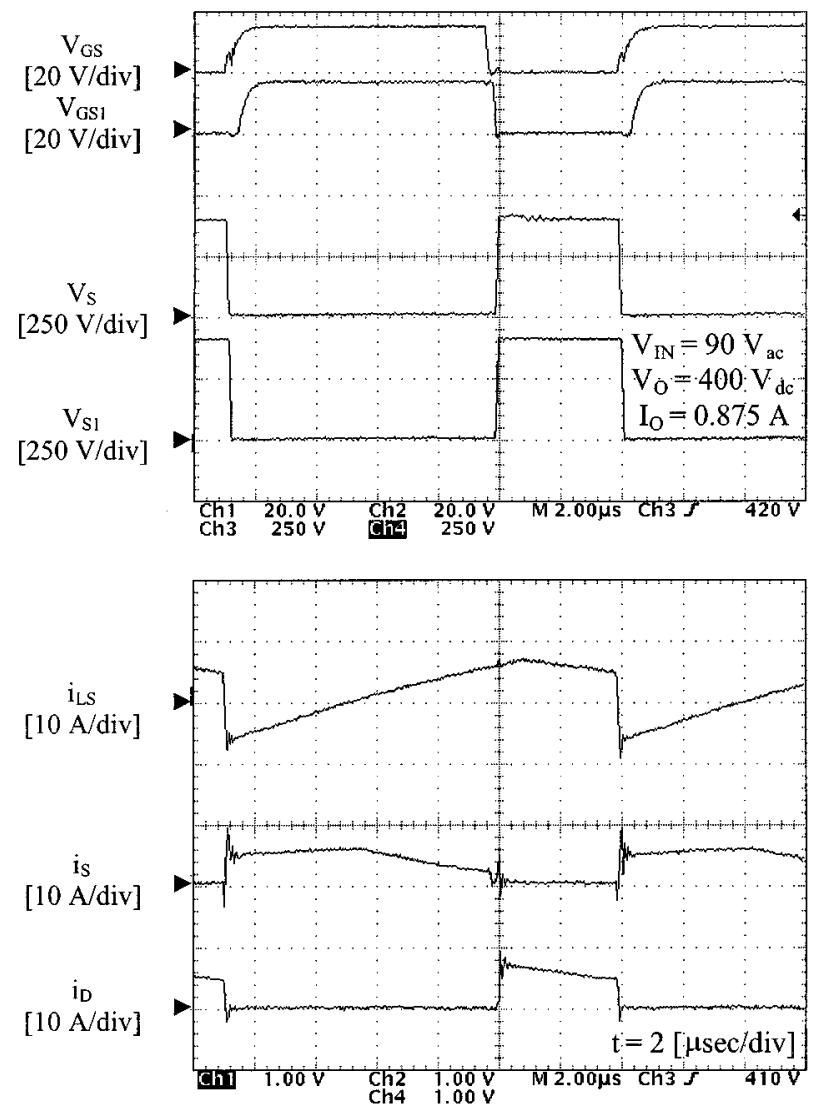

Fig. 9. Measured key waveforms of experimental converter at $P_{O}=350 \mathrm{~W}$ and $V_{\mathrm{IV}}=90 \mathrm{~V}_{\mathrm{ac}}$. Time base: $2 \mu \mathrm{s} /$ div.

current $I_{\mathrm{RR}}$ is reduced to approximately $4 \mathrm{~A}$, which corresponds to a recovered charge of approximately $100 \mathrm{nC}$.

The key waveforms of the experimental prototype at light load operation is shown in Fig. 9. When input current $I_{\mathrm{IN}}$ is smaller than the peak resonant current $I_{\mathrm{LS}(\mathrm{PK})}$, the charge balance of clamp capacitor $C_{C}$ is completed during the switch-on period as shown in Fig. 9.

Figs. 10 and 11 show the measured waveforms of the input line current and clamp capacitor voltage $V_{C}$ of the prototype rectifier delivering $1.2 \mathrm{~kW}$ at $90 \mathrm{~V}$ and $265 \mathrm{~V}$ input voltages, respectively. Since the maximum duty cycle is not limited by the addition of the active snubber circuit, the input current waveforms with and without the active snubber circuit are nearly identical. The power factor of the prototype circuit measured at $90 \mathrm{~V}$ and $265 \mathrm{~V}$ input voltages are $99.3 \%$ and $98.4 \%$, respectively.

Fig. 12 shows the measured efficiencies of the experimental converter with and without the active snubber at the minimum and maximum line voltages as functions of the output power. As can be seen from Fig. 12, for both line voltages the active snubber improves the conversion efficiency in the entire measured power range ( $200 \mathrm{~W}$ to $1.2 \mathrm{~kW}$ ). Nevertheless, the efficiency improvement is more pronounced at the minimum line and higher power levels where the reverse-recovery losses are greater. Specifically, at the maximum line $\left(265 \mathrm{~V}_{\mathrm{rms}}\right)$, the efficiency improvement at $1.2 \mathrm{~kW}$ is $0.9 \%$. However, at the minimum line, the implementation without the active snubber cannot deliver more than approximately $900 \mathrm{~W}$ due

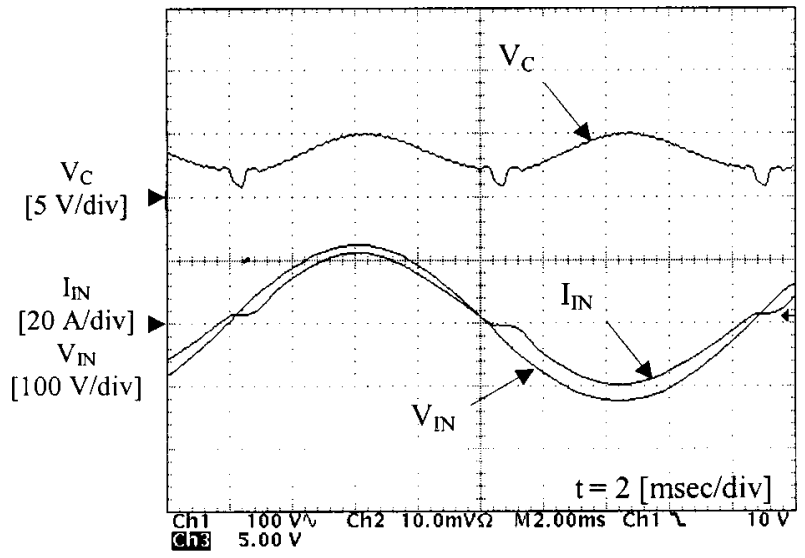

Fig. 10. Measured clamp capacitor voltage $V_{C}$, input current $I_{\mathrm{IV}}$, and input voltage $V_{\mathrm{IV}}$ waveforms of experimental converter at $P_{O}=1.2 \mathrm{~kW}$ and $V_{\mathrm{IV}}=$ $90 \mathrm{~V}_{\text {ac. }}$. Time base: $2 \mathrm{msec} /$ div.

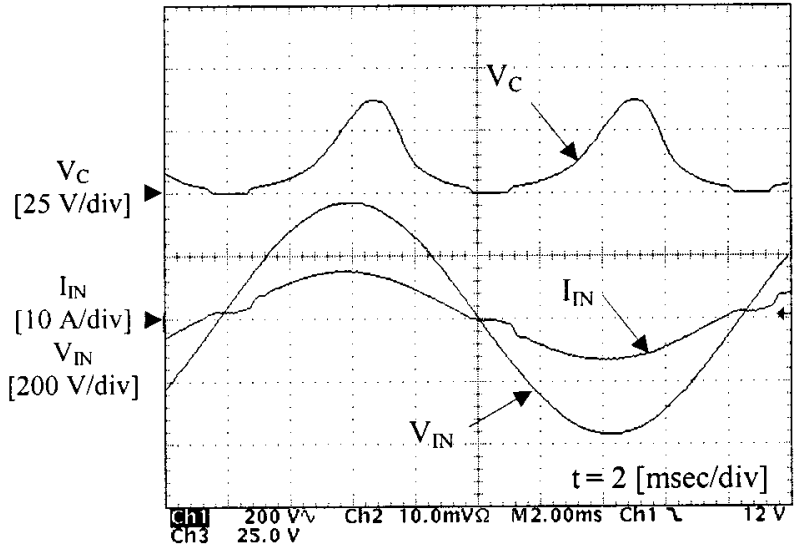

Fig. 11. Measured clamp capacitor voltage $V_{C}$, input current $I_{\mathrm{IN}}$, and input voltage $V_{\mathrm{IN}}$ waveforms of experimental converter at $P_{O}=1.2 \mathrm{~kW}$ and $V_{\mathrm{IN}}=$ $265 \mathrm{~V}_{\mathrm{ac}}$. Time base: $2 \mathrm{msec} / \mathrm{div}$.

to the thermal runaway of the switch caused by the excessive reverse-recovery losses. Even at $P_{O}=900 \mathrm{~W}$, the active snubber improves the efficiency by approximately $3.4 \%$, which translates into approximately $30 \%$ reduction of the losses.

Fig. 13 shows the measured temperatures of the experimental converter with and without the active snubber at the minimum line voltage as functions of the output power. The ambient temperature was approximately $26^{\circ} \mathrm{C}$ during the measurements. As can be seen from Fig. 13, at the same power levels, the temperatures of the semiconductor components in the implementation with the active snubber are significantly lower than those in the implementation without the snubber. As indicated in Figs. 12 and 13, at the maximum line (265 $\left.\mathrm{V}_{\mathrm{rms}}\right)$ and full power $(1.2 \mathrm{~kW})$, the case temperatures of the boost rectifier and boost switch in the implementation with the snubber are $T_{d}=37^{\circ} \mathrm{C}$ and $T_{S}=35^{\circ} \mathrm{C}$, respectively, whereas the corresponding temperatures in the implementation without the snubber are $T_{d}=41^{\circ} \mathrm{C}$ and $T_{S}=39^{\circ} \mathrm{C}$. Similarly, at the minimum line voltage $\left(90 \mathrm{~V}_{\text {rms }}\right)$ and full power, the rectifier and switch temperatures in the implementation with the snubber are $T_{d}=41^{\circ} \mathrm{C}$ and $T_{S}=86^{\circ} \mathrm{C}$. As can be seen from Figs. 12 and 13, the implementation without the snubber cannot deliver the full power of $1.2 \mathrm{~kW}$ at the minimum line because 


\section{EFFICIENCY [\%]}

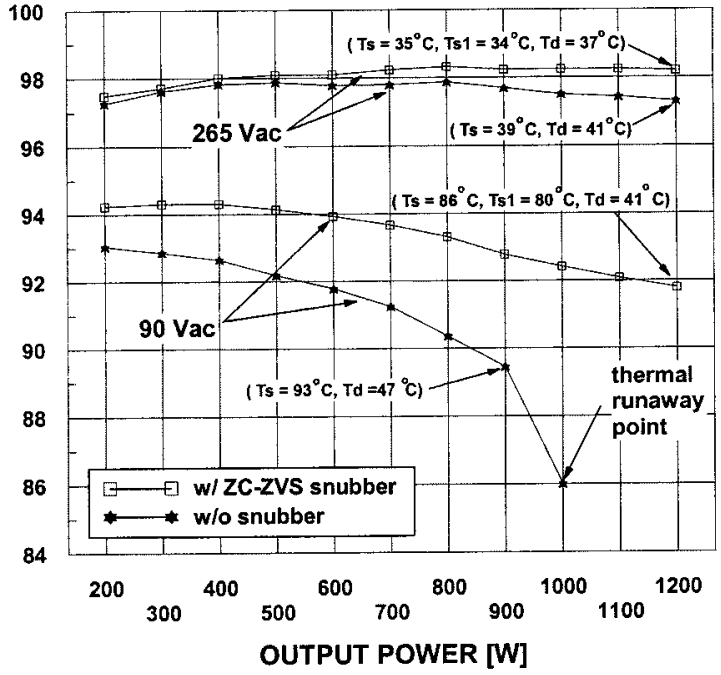

Fig. 12. Measured efficiencies of the experimental converter with and without $\mathrm{ZC}-\mathrm{ZVS}$ active snubber at the minimum and maximum line voltages as functions of the output power. Note that the maximum possible output power for the implementation without the snubber is limited to $900 \mathrm{~W}$.

\section{TEMPERATURE [deg C]}

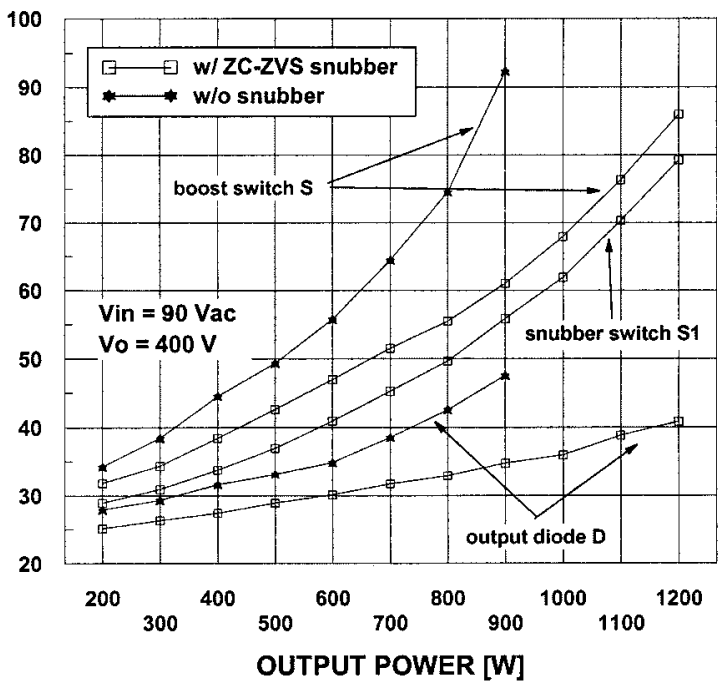

Fig. 13. Measured switch temperature of the experimental converter with and without ZC-ZVS active snubber at the minimum line voltage as functions of the output power

the rectifier becomes thermally unstable at approximately 900 W. In fact, for the implementation without the snubber the temperature of the boost switch is $T_{S}=93{ }^{\circ} \mathrm{C}$ at $900 \mathrm{~W}$, which is significantly higher than the temperature of the switches $\left(T_{S}=61^{\circ} \mathrm{C}, T_{S 1}=56{ }^{\circ} \mathrm{C}\right.$ ) in the implementation with the snubber at the same output power.

\section{CONCLUSION}

An active-snubber technique which reduces the reverse-recovery-related losses of the rectifier and also provides lossless switching for the main and auxiliary switches is described. A complete design procedure of a boost input-current shaper with the proposed active snubber is presented. Also, performance evaluations on a 1.2-kW high-power-factor boost rectifier for server applications are given. It is shown that the proposed active-snubber technique can significantly extend the maximum power range at which a fast-recovery rectifier can be reliably employed.

\section{REFERENCES}

[1] K. Wang, F. C. Lee, G. Hua, and D. Borojević, "A comparative study of switching losses of IGBTs under hard-switching, zero-voltage-switching, and zero-current-switching," in Proc. IEEE Power Electron. Spec. Conf.(PESC) Rec., June 1994, pp. 1196-1204.

[2] G. Hua, X. Yang, Y. Jiang, and F. C. Lee, "Novel zero-current-transition PWM converters," in Proc. IEEE Power Electron. Spec. Conf. (PESC) Rec., June 1993, pp. 538-544.

[3] K. Wang, G. Hua, and F. C. Lee, "Analysis, design and experimental results of ZCS-PWM boost converters," in Proc. Int. Power Electron. Conf. Proc., Yokahama, Japan, Apr. 1995, pp. 1202-1207.

[4] Y. Khersonsky, M. Robinson, and D. Gutierrez, "New fast recovery diode technology cuts circuit losses, improves reliability," Power Conv. Intell. Motion (PCIM) Mag., pp. 16-25, May 1992.

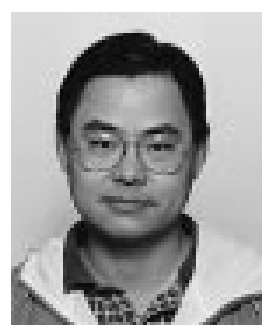

Yungtaek Jang (S'92-M'95-SM'01) was born in Seoul, Korea. He received the B.S. degree from Yonsei University, Seoul, in 1982, and the M.S. and Ph.D. degrees from the University of Colorado, Boulder, in 1991 and 1995, respectively, all in electrical engineering.

From 1982 to 1988, he was a Design Engineer at Hyundai Engineering Co., Seoul. From 1995 to 1996, he was a Senior Engineer at Advanced Energy Industries, Inc., Fort Collins, CO. Since 1996, he has been a Senior Researcher at the Power Electronics Laboratory, Delta Products Corporation, Research Triangle Park, NC. He holds 13 U.S. patents. His research interests include resonant power conversion, converter modeling, control techniques, and low harmonic rectification.

Dr. Jang received the IEEE TRANSACTIONS ON POWER EleCtronics Prize paper award for best paper published in 1996.

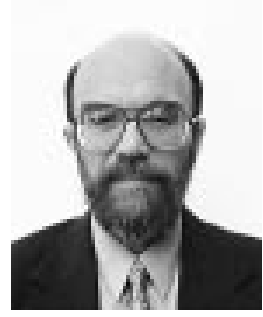

Milan M. Jovanović (F'01) was born in Belgrade, Yugoslavia. He received the Dipl. Ing. degree in electrical engineering from the University of Belgrade, the M.S.E.E. degree from the University of Novi Sad, Yugoslavia, and the $\mathrm{Ph}$. D. degree in electrical engineering from Virginia Polytechnic Institute and State University (Virginia Tech), Blacksburg.

He was on the Faculty at the Institute for Power and Electronics, University of Novi Sad, from 1976 to 1983. From 1983 until 1991, he was with the Virginia Power Electronics Center (VPEC), Virginia Tech. Since August 1991, he has been with Delta Products Corporation (the U.S. subsidiary of Delta Electronics, Inc., Taiwan, one of the world's largest manufacturers of power supplies). Currently, he is the Vice President for Research and Development of Delta Products Corporation, Research Triangle Park, NC. His 26 year experience includes the analysis and design of high-frequency, high-power-density power processors; modeling, testing, evaluation, and application of high-power semiconductor devices; analysis and design of magnetic devices; and modeling, analysis, and design of analog electronics circuits. His current research is focused on power conversion and management issues for portable data-processing equipment, design optimization methods for low-voltage power supplies, distributed power systems for server and telecom applications, and power-factor-correction techniques. He has published more than 150 journal and conference papers and holds 19 U.S. patents related to power conversion technologies. In addition, he has presented more than 50 short courses, professional seminars, and workshops in the U.S., Europe, and Asia.

Dr. Jovanović is a member of Sigma Xi, Phi Kappa Phi, and Eta Kappa Nu. He served as Secretary of the IEEE Power Electronics Society (PELS) Meetings Committee from 1991 to 1993, and as a Program Co-Chairman of the 1994 Power Electronics Specialist's Conference (PESC), Taipei, Taiwan. He was also an At-Large Member of PELS Administrative Committee from 1995 to 1997. 